\title{
The Effect of Unemployment Rate on the Gross Domestic Product in Nigeria (A Bayesian Approach)
}

\author{
By \\ Victor Agboli \\ Department of Mathematics, University of Lagos, Nigeria \\ victoragboli@gmail.com
}

\begin{abstract}
This study investigates the impact of unemployment on the Gross Domestic Product (GDP) of Nigeria for a period of 28 years (1990-2018). The study focuses on the relationship between unemployment and economic growth in Nigeria (GDP). The method used in this study is the Bayesian Linear Regression Analysis, the major findings was that unemployment has a positive impact on the economic growth of Nigeria. Some suggestions and policy recommendations were made based on the findings.
\end{abstract}

Key Words: GDP, Unemployment rate, Bayesian, Prior Distribution, Posterior Distribution

\section{INTRODUCTION}

One of the greatest challenges facing the Nigeria economy is unemployment which has been on the rise over the years. According to Njoku (2011), the total labour force in Nigeria is made up of persons aged between 15-65 years excluding students and those medically unfit available for work but do not find work. The International Labour Organization (ILO) defined unemployment as the measure of the prevalence of unemployment and it is calculated as a percentage by dividing the number of unemployed individuals by all individuals in the labour force. Unemployment could be frictional, seasonal, structural and cyclical. The kind of unemployment in Nigeria is structural in nature, i.e. there is a huge difference between demand and supply of labour. The rising population of the country is faster than the job opportunities, a situation in which the birth rate is rising, death rate falling and the population growth is between 2.5\%-3\%, unemployment is bound to exist. There has been a total neglect of the agricultural and manufacturing sectors and consequent mass exodus of able bodied youths from the rural to urban areas in search of greener pastures. This reduces employment in agriculture and puts pressure on the existing jobs (Anyanwu 1995). Official figures from the Nigerian Bureau of Statistics has it that the unemployed persons was 30 million about 19.70 percent. This statistics is scary and poses a threat to the economic development, security of Nigeria. Currently, the insecurity challenges such as insurgency, public violence and societal crime has been on the increase and the perpetrators of these occurrences are largely believed to be currently unemployed or underemployed. Unemployment is a problem both economically and socially. Unemployment in Nigeria has resulted in more people who do not have purchasing power. Less consumption has led to lower production and economic growth has been affected.

Economic growth is a fundamental requisite to economic development. Essentially, economic growth is associated with policies aimed at transforming and restructuring the real economic sectors. Ever since independence in 1960, the challenge facing the Nigerian economy has been how to increase economic growth in order to reduce unemployment rate and by extension extreme poverty, strengthen democratic and political stability and diminish the incidence of crime and violence (Ismaila and Imoughele 2015). The GDP is one of the most widely used measures of an economy's output or production. So Gross 
Domestic Product of a country can be defined as the monetary value of all finished goods and services produced in a country within a country's border within a specific time period which can be monthly, quarterly, or annually. The GDP is an accurate indication of an economy's size and is probably the single best indicator of economic growth. Gross domestic product are of two types; nominal and real GDP. Real GDP is an inflation-adjusted measure that reflects the value of all goods and services produced by an economy in a given year. It is often referred to as "inflation-corrected" GDP. Nominal GDP is a macroeconomic assessment of the value of goods and services using current prices in its measure. Nominal GDP is also referred to as the current dollar GDP. Economists typically use nominal GDP when comparing different quarters of output within the same year. But when comparing GDP across more than one year, real GDP is used. Real GDP is a much better index for expressing the output of an economy (Investopedia, 2018), as it takes into account the fluctuating value of goods and services when expressed in monetary terms. It therefore gives Economists a better idea of the total national output of a country. It is on this basis that this paper examines unemployment within the scope of the Nigerian economy and its impact of the economic growth for the selected years.

\section{LITERATURE REVIEW}

In examining unemployment and economic growth around the world, many studies have proved the existent of conflicting relationship between economic growth and unemployment; with some showing a positive relationship while others show an inverse relationship.

With the evidence that the size of the workforce directly impacts on a country's GDP, (Njoku and Ihugba 2011) looks into the relationship between unemployment and growth in Nigeria (1985-2009). The study found out that the economy grew by 55.5 percent between 1991-2006, and the population increased by 36.4 percent. Ordinary, this would have led to a decrease in unemployment rate but rather, unemployment rate increased by 74.8 percent. The study discovered a negative relationship between unemployment and economic growth only when the growth is motivated by the agricultural sector. It also recommended that the agricultural sector as a medium of reducing unemployment in Nigeria.

Using the first difference and output gap models of Okun's law, (Arewa and Nwakanma, 2012) conducted an empirical evaluation of the relationship between output and unemployment. The study discovered no evidence to support the validity of the Okun's law in Nigeria.

(Airi et al, 2016) investigates the impact of unemployment on Nigeria's economy (1980-2010(. By adopting the Ordinary Least Squares Regression (OLS), the findings showed that unemployment has a negative effect on the gross domestic product (GDP) of Nigeria economy.

(Fuad, 2011) investigates the relationship between unemployment and economic growth in Jordan through the implementation of Okun's law. Using data covering the period 1970-2008, time series techniques, Augmented Dickey-Fuller (ADF) for unit root, co-integration test and a simple regression are used to test the relation and obtain estimates for the Okun's coefficient, study the relationship between unemployment and economic growth. The results revealed that Okun's law cannot be confirmed for Jordan.

Evidence from Central Bank of Nigeria (CBN) 2015 Statistical Bulletin revealed unemployment rate has been oscillating upwards from 5.3 percent in 1986 to 24.7 percent by 2012. Although unemployment rates was at its lowest rates of 1.8 percent and 0.2 percent in 1995 and 1990 respectively (Central Bank of Nigeria, 2015). This shows that in year 1990 and 1995, unemployment responded significantly to economic growth as against other years where unemployment kept growing despite the significant economic growth recorded in Nigeria. Visibly, this indicates that the Okun's law which indicates an inverse relationship between economic and unemployment is not applicable in Nigeria. 
(Obadan and Sagbamah, 1997) observed that economic growth and employment move in the same direction. All things being equal, the higher the growth rate, the higher the employment and vice versa. Thus, economic growth and unemployment have a negative relationship.

(Phillip, 1958) in his study on unemployment and rate of money wage in the British economy noted that increase in unemployment causes a drop in inflation. He concluded that as employment increase, inflation rises, but as unemployment increases, inflation falls as the purchasing power of the economy becomes weaker.

(Okun, 1962) propounded what is presently known as the "Okun's law". He observed that as unemployment falls by 1 percent, gross domestic product increase by 3 percent. This was faced with criticism as it only held in the United States of America alone.

(Sadiku, Ibraimi, 2015) empirically examined unemployment relation with growth in FYR Macedonia using VAR approach with a quarterly based data from 2000-2012. It was observed that no negative relationship between unemployment and economic growth as propounded by Okun's law, and also no direction of causality between unemployment and economic growth.

(Muhammad, Inuwa and Oye, 2011) examined the implication of unemployment on gross domestic product in Nigeria over a period of nine years (2000-2008) using regression analysis. Findings showed that unemployment has an enormous effect (over 65\%) on the making of the Niegrian GDP and there exist an inverse relationship between unemployment and GDP.

(Babalola, Saka and Adenuga, 2013) validates Okun's law in Nigeria using VAR co-integratiob to compare the two models (short and long run) from 1980-2012. It was observed that unemployment rate as an independent variable was positive and also positive for real GDP growth as an independent variable. These findings are contrary to the Okun's law of unemployment-economic growth relationship.

(Onwanchukwu, 2015) examined the impact of unemployment on the economic growth in Nigeria from 1985-2010, using ordinary least squares regression techniques. His findings shows that unemployment does not have a significant impact on the economic growth of Nigeria.

Many studies such as (Ademola and Badiru, 2016), (Akeju and Olanipeun, 2014), (Arewa and Nwakanma, 2012) confirm positive relationship between unemployment and economic growth, (Sodipe, 2008) reported mixed evidence and some others showed inverse or negative relationship.

\section{DATA SOURCE AND RESEARCH METHODOLOGY}

\section{a) Theoretical Underpinning and Model Specification}

The theory that can be used in explaining the relationship between growth and unemployment is Okun's law. Okun's law propounded by Arthur Okun is an empirical observation on the relationship between unemployment rate and economic growth. Using a Bayesian approach to study this relationship is fascinating. First off a background of the Bayesian approach.

The Bayesian Approach (methodology) has its foundation in the Bayes' Theorem which was introduced by Reverend Thomas Bayes as a means of infusing our old knowledge and current knowledge to make informed decisions. Bayes' Theorem tells us how to update our beliefs in the light of new evidence. 


\section{I) Statement of the Bayes' Theorem}

Let $\varphi$ be a sample space and let A and B be two events in $\varphi$. Bayes' theorem relates the conditional and marginal probabilities of random events $\mathrm{A}$ and $\mathrm{B}$ :

$p(A \mid B)=\frac{p(B \mid \mathrm{A}) \mathrm{P}(\mathrm{A})}{P(B)}=\frac{L(B \mid \mathrm{A}) \mathrm{P}(\mathrm{A})}{P(B)}$

$L(A \mid B)=p(A \mid B)$ is the likelihood of $\mathrm{A}$ given $\mathrm{B}$ for a fixed value of $\mathrm{B}$.

Each term in Bayes' theorem has a conventional name:

I. $\quad p(A)$ is the prior probability or marginal probability of $\mathrm{A}$.

II. $\quad p(A \mid B)$ is the conditional probability or posterior probability of observing $\mathrm{A}$, given $\mathrm{B}$ is true.

III. $\quad p(B \mid \mathrm{A})$ is the conditional probability of observing $\mathrm{B}$, given $\mathrm{A}$ is true.

IV. $p(B)$ is the prior or marginal probability of $\mathrm{B}$.

With this terminology, the theorem can be written as:

$$
\text { Posterior }=\frac{\text { Likelihood } \times \text { Prior }}{\text { Normalizing Constant }}
$$

Clearly, the posterior distribution is proportional to the prior distribution times the likelihood.

\section{II) Bayesian Analysis of the Regression Model}

The quantity of primary interest, $\mathrm{y}$ is called the response or outcome variable; we assume it is continuous. The variables $x=\left(x_{1}, \ldots, x_{k}\right)$ are called the explanatory variables and maybe discrete or continuous. We use y to denote the vectors of outcomes for $\mathrm{n}$ subjects and $X$ as the $n \times k$ matrix of explanatory variables.

The simplest and the most widely used version of this model is the normal linear model given by

$$
E\left(y_{i} \mid \beta_{i} X\right)=\beta_{1} X_{i 1}+\cdots+\beta_{k} X_{i k}
$$

For $i=1,2, \ldots, n$. For many applications, $X_{i 1}$ is fixed at 1 , so that $\beta_{i} X_{i 1}$ is a constant $\forall i$. In the simplest case, called Ordinary Linear Regression, the observation errors are independent and have equal variance. In vector notation,

$$
y \mid \beta, \sigma^{2}, X \sim N\left(X \beta, \sigma^{2} I\right)
$$

A convenient non-informative prior distribution is uniform on $(\beta, \sigma)$ or equivalently,

$p\left(\beta, \sigma^{2} \mid X\right) \propto \sigma^{-2}$

The conditional posterior distribution of the parameter $\beta$, given $\sigma^{2}$, is the exponential of a quadratic form in $\beta$ and hence normal. We use the notation 


$$
\beta \mid \sigma^{2}, y \sim N\left(\widehat{\beta}, V_{\beta} \sigma^{2}\right)
$$

Where after completing the square, we have,

$$
\begin{aligned}
& \hat{\beta}=\left(X^{T} X\right)^{-1} X^{T} y \\
& V_{\beta}=\left(X^{T} X\right)^{-1}
\end{aligned}
$$

For any analysis based on an improper prior distribution. It is important to check that the posterior distribution is proper, i.e. it has a finite integral. The prior distribution is proper as long as

$$
\begin{aligned}
\text { I. } & n>k \\
\text { II. } & \text { The rank of } X \text { equals } k
\end{aligned}
$$

We most times draw samples from the posterior distribution $p\left(\beta, \sigma^{2} \mid \mathrm{y}\right)$ by computing $\hat{\beta}, V_{\beta}$ and $s^{2}$, drawing $\sigma^{2}$ from the scaled inverse- $\chi^{2}$ distribution and $\beta$ from the multivariate normal distribution. However, this is actually accomplished using a software like R, WinBugs etc.

\section{b) Data Sources and Technique Description}

Secondary data has been used in this study. Data on Gross Domestic Product (GDP) was sourced from the publications of Central Bank of Nigeria (CBN) Statistical Bulletin and data on the unemployment rate was sourced from the National Bureau of Statistics (NBS).

To estimate the model, a flat (uniform) prior distribution was used since I didn't have prior knowledge about the parameters. This prior distribution was joined with the likelihood to give the posterior distribution of the parameters. The Pearson correlation coefficient was also calculated to know the magnitude and direction of the relationship between GDP and Unemployment Rate.

The posterior predictive distribution was gotten for future predictions of GDP given a value of Unemployment Rate.

The data used in this study was analysed using R Statistical Software, installing libraries such as arm, Bolstad, McMcpack, CODA, BayesSummaryStatLM, bayesSurv, bayesplot.

\section{Statement of Problem}

In this study, the research problem is to estimate the effect of unemployment rate on the Gross Domestic Product of Nigeria using Bayesian Linear Regression Analysis

\section{Significance of Study}

a). This study would help policy makers as well as investors in making decisions about key areas of the economy.

b). This study would help the to improve predictive performance of the economy

c). This study would also help provide information to the society about how the Gross Domestic Product (GDP) affects them, directly or indirectly. 


\section{RESULTS AND DISCUSSION}

Table 4.1 shows summary statistics of the Gross Domestic Product and Unemployment rate in Nigeria between the periods of 1985-2018.

Table 4.1. Descriptive Statistics

\begin{tabular}{|l|c|c|}
\hline & $\begin{array}{l}\text { GDP } \\
\text { Dollars) }\end{array}$ & (Billion \\
\hline Minimum & 27.75 & 1.80 \\
\hline Mean & 192.26 & 9.05 \\
\hline Median & 84.71 & 7.60 \\
\hline Maximum & 568.50 & 23.10 \\
\hline
\end{tabular}

The findings as seen in table 4.1 showed that the Gross Domestic Product of the Nigerian economy was on the average of 192.26 Billion Dollars between the periods of 1985-2018. Also the minimum and maximum GDP was 27.75 Billion Dollars and 568.50 Billion Dollars respectively. This high growth in the economy might not be unconnected to the aftermath effect of the structural adjustment program which led to the expansion of the informal sector. In the same vein, unemployment rates stood at 9.05 percent on the average from 1985-2018 in Nigeria. The maximum unemployment rate from 1985-2018 was 23.10 percent in the year 2018, while the minimum unemployment rate in Nigeria stood at 1.80 percent in the year 1995 .

This shows that growth in Nigeria's GDP has not really reduced unemployment as one would expect. The reason may not be farfetched from the empirical evidence by (Njoku and Ihugba, 2011) who reported that growth in Nigeria has been motivated by the oil sector which can accommodate only a few numbers of the growing Nigerian labour force.

Table 4.2 shows the summary statistics of the posterior distribution and the marginal posterior inclusion probabilities.

Table 4.2. Posterior Distribution Summary

\begin{tabular}{|c|l|l|l|c|}
\hline Parameter & Mean & SD & $\mathbf{9 5 \%}$ CI & $\boldsymbol{P r}\left(\boldsymbol{\beta}_{\boldsymbol{j}}=\mathbf{0} \mid\right.$ data $)$ \\
\hline$\beta_{0}$ & 60.72 & 52.09 & $(-39.69,163.59)$ & 1.000 \\
\hline$\beta_{1}$ & 14.50 & 4.92 & $(4.66,24.15)$ & 1.000 \\
\hline$\sigma^{2}$ & 25894.59 & 6985.52 & $(15563,42392.31)$ & - \\
\hline
\end{tabular}

The findings as seen in table 4.2 showed that the intercept parameter $\left(\beta_{0}\right)$ has a mean of 60.72 and a standard deviation of 52.09. The parameter of the unemployment rate $\left(\beta_{1}\right)$ has a mean of 14.50 and a standard deviation of 4.92. Meanwhile, the variance $\left(\sigma^{2}\right)$ has a mean of 25894.59 and a standard deviation of 6985.52 .

Just like in the Frequentist Approach, we have what we call confidence interval, but in Bayesian Approach, such intervals are called credible interval. The credible interval is used to express our belief in certain parameter values. From table 4.2 , the credible interval for the intercept parameter $\left(\beta_{0}\right)$ is ($39.69,163.59)$. We say that there is a $95 \%$ probability that the true population value of the intercept parameter $\left(\beta_{0}\right)$ is between -39.69 and 163.59 . In the same vein, we say there is a $95 \%$ probability that the true population value of the parameter of the unemployment rate $\left(\beta_{1}\right)$ is between 4.66 and 24.15. The marginal posterior inclusion probability provides a weight of evidence that a predictor should be included. From the table 4.2, the marginal posterior inclusion probability of $\beta_{0}$ and $\beta_{1}$ was both 1.000 . This means $\beta_{0}$ and $\beta_{1}$ are both significant and should be included in the model. 
Figure 4.1. Traceplot and Density plots of the parameters
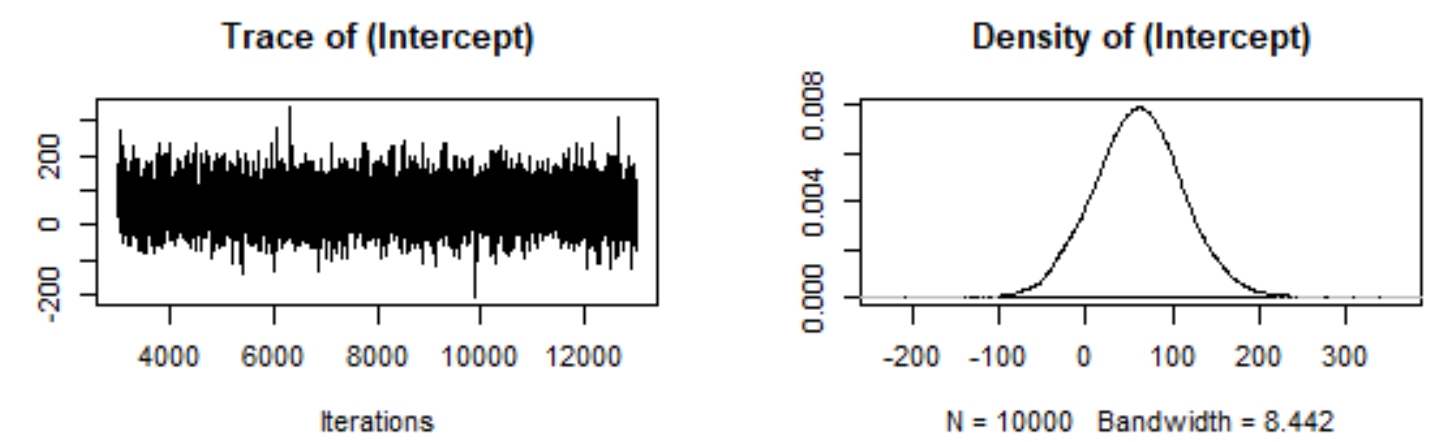

Trace of Unemployment_Rate

\section{Density of Unemployment_Rate}
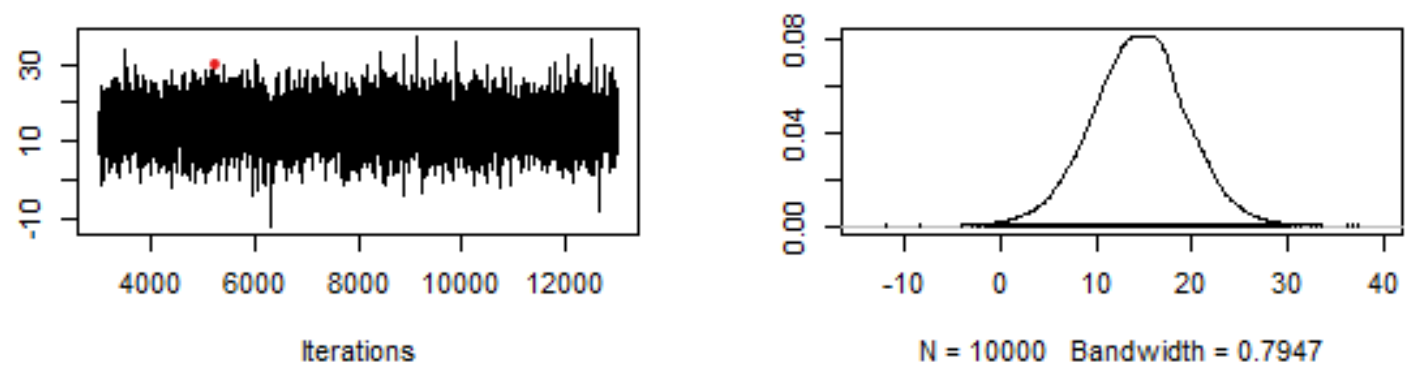

Trace of sigma2

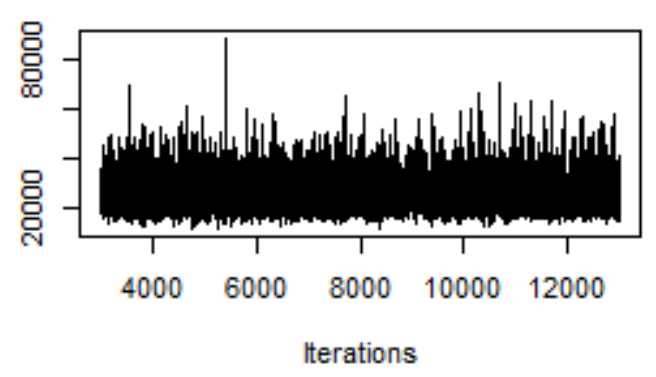

Density of sigma2

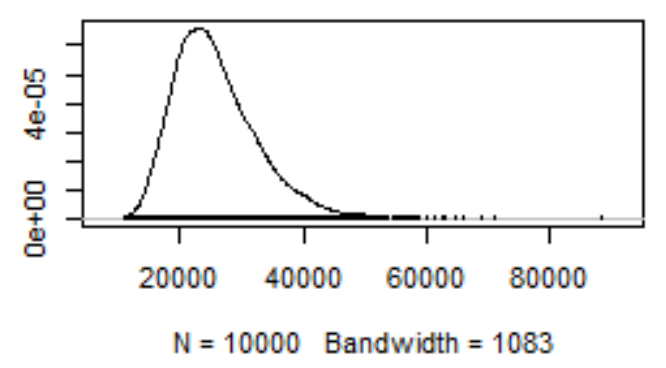

From figure 4.1, shows the density plot of the intercept parameter which peaked at 60.72 . The density plot of the unemployment rate parameter is also shown and peaked at 14.50. In the same vein, the density plot of the variance of also shown and peaked at 25894.59.

The Pearson correlation coefficient of the Gross Domestic Product and Unemployment rate is 0.4758, which means that there is a weak positive relationship between the variables.

Just like in the Frequentist Approach, we can make predictions about the dependent variable given the fixed value(s) of the independent variable(s). Similarly, in the Bayesian Approach, we can make predictions for the future values of the dependent variable. Since our Bayesian estimates of the regression model are significant, we can proceed to make prediction. When predicting the output for a single data point using Bayesian Linear Regression Analysis, we don't get a single value, rather get a distribution called the Posterior Predictive Distribution. 
Fig 4.2 Posterior Predictive Density Plot of GDP

\section{Posterior Prediction Density}

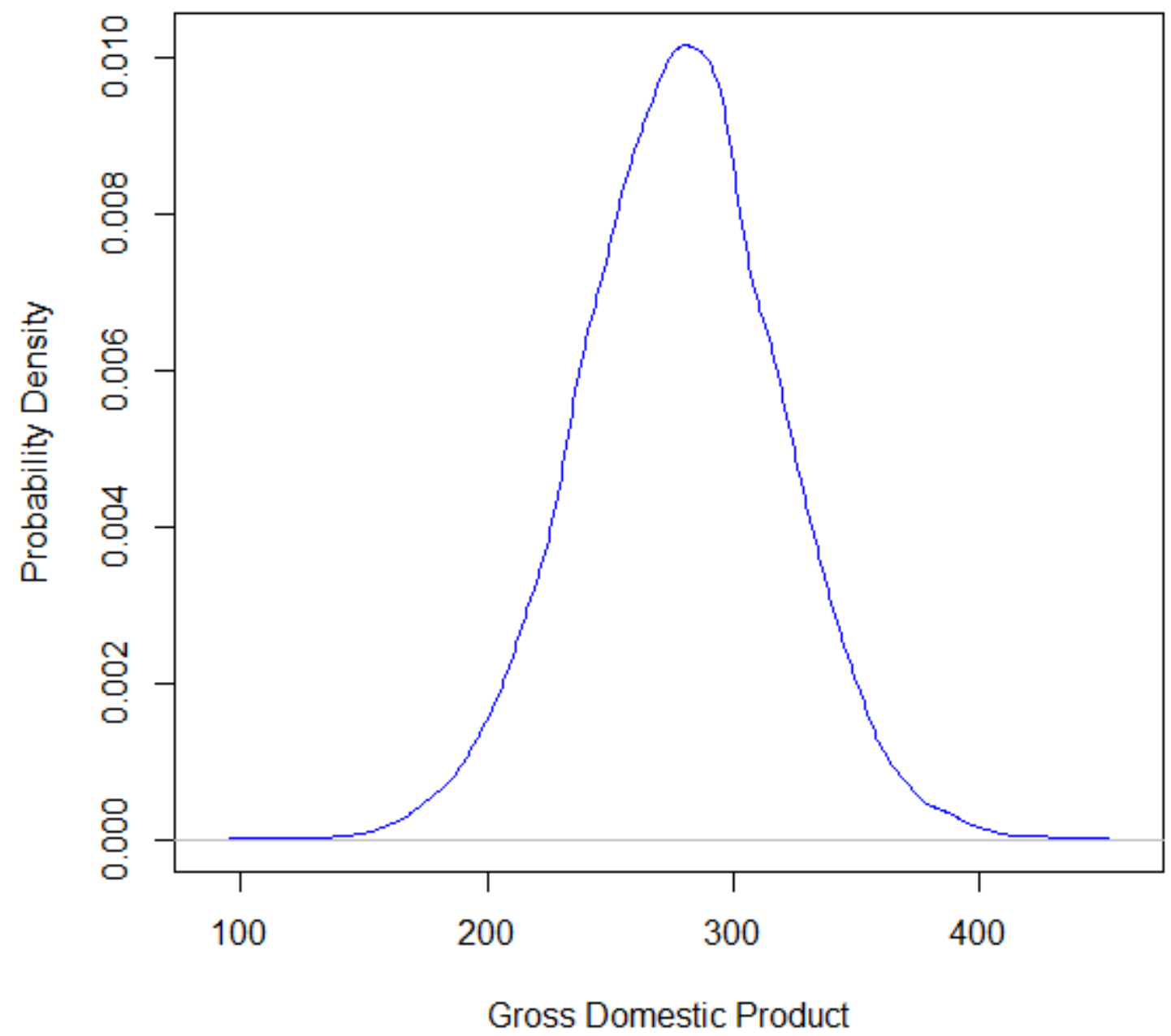

Fig 4.2 shows the posterior predictive distribution of the Gross Domestic Product given that the unemployment rate is $15 \%$. Clearly, the probability of the Gross Domestic Product peaked around 280 Billion Dollars, but the full estimate is a range of values.

Fig 4.3 shows the posterior predictive distribution of the Gross Domestic Product given that the unemployment rate is $25 \%$. Clearly, the probability of the Gross Domestic Product peaked around 430 Billion Dollars, but the full estimate is a range of values.

Which corroborates our initial result that an increase in unemployment rate increases the Gross Domestic Product, and vice versa. 
Fig 4.2 Posterior Predictive Density Plot of GDP

\section{Posterior prediction density}

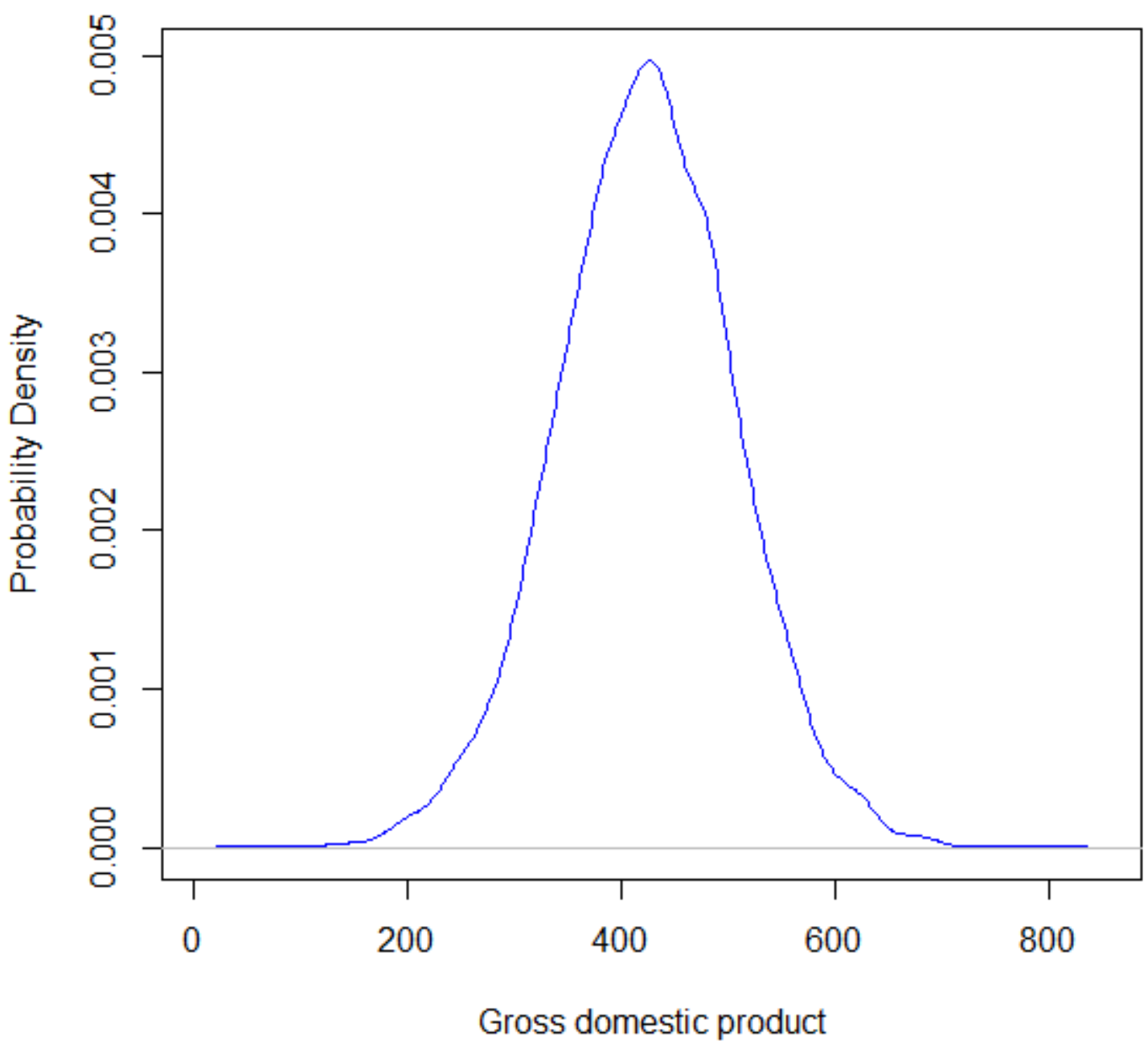

\section{CONCLUSION AND RECOMMENDATIONS}

The aim of this study was to study the relationship between the Gross Domestic Product and the Unemployment rate using Bayesian Linear Regression Analysis. Based on the result of the analysis, we have seen that from the 34 years considered, the relationship between the Gross Domestic Product and the Unemployment rate was positive. This seems to be abnormal because according to the Okun's law in Economics, an increase in the Gross Domestic Product of a country would lead to a decrease in unemployment.

This study found out that the reverse of the Okun's law is valid in Nigeria which is in-line with the study conducted by (Babalola et al, 2013) and (Muhammed et al, 2014). However, there seem to be an explanation to this anomaly. It is evident that employment will only increase if GDP is rising faster than productivity. All things being equal, the greater the amount of goods and services produced, the greater the labour required for production; because economic growth and employment goes hand in hand. Also, the kind of unemployment in Nigeria happens to be structural in nature. Another factor is that Nigeria is a one sector dependent economy, Nigeria depends heavily on the oil sector which happens to be a major source of revenue to the nation. The years under consideration happens to have the highest crude oil price per barrel thus covering for the lapses caused by unemployment. 
Based on the findings in this research, the following recommendations are made:

i. Diversification of the Nigerian economy is necessary so as to reduce the over dependence on the crude oil sector for job opportunities. Sectors such as Agriculture, Manufacturing etc. should be harnessed as a means to reduce unemployment in Nigeria.

ii. Since the kind of unemployment is structural in nature, Government and the relevant agencies needs to work hand in hand to formulate policies to encourage self-employment and reduce cost of doing business by removing structural rigidities that exists in the country so as to achieve swift and sustained economic growth.

iii. There is a need to make the Nigerian business space investment friendly, by providing stable power supply, good transportation network for easy movement of goods and services to meet the demands, etc. leading to industrial expansion and economic growth. This would provide employment opportunities for the people.

This result is statistically significant to the economy of Nigeria and would help alleviate unemployment.

\section{REFERENCES}

Central Bank of Nigeria (2018), Nigeria Bureau of Statistics (2018). Statistical Bulletin

Akutson Seth, Messiah Abaka John and Araf Yakubu Dalhatu (2018), "The impact of Unemployment on Economic growth in Nigeria: An Application of Autoregressive Distributed Lag (ARDL) Bound Testing”, Summerianz Journal of Business Management and Marketing, 2018, Vol. 1, No. 2, pp. 37 46, ISSN(e): 2617-0175, ISSN(p): 2617-1724

Olawunmi Omitogun, Adedayo Emmanuel Longe (2017), "Unemployment and Economic Growth in Nigeria in the $21^{\text {st }}$ Century: VAR Approach”, ECONOMICA, Vol. 13, no. 5, pp. 155-168

Eche Emmanuel, Ibrahim Magaji, Ishaku, R.N (2017), "Unemployment Challenges and Economic Growth in Nigeria”, Nigerian Journal of Management Sciences Vol. 6, No. 1, 2017

Inuwa Ibrahim, Muhammad Shakil Ahmad (2011), "Unemployment in Nigeria: Implication on the Gross Domestic Product over the years”, Int. J. Eco. Res., 2011, 2(1), 66-71

Njoku, A., Ihugba, O. (2011), “Unemployment and Nigerian Economic Growth (1985-2009)”, Proceedings of the 2011 International Conference on Teaching, Learning and Change (IATEL)

O.B, Akanbi, J.F Ojo and M.O Oluneye (2018), "Modelling GDP in Nigeria using Bayesian Model Averaging”, International Journal of Applied Science and Mathematics, Vol. 5, issue 3, ISSN(online): $2394-2894$ 
Richard C. Osadume (2018), "Foreign Exchange Rate Nexus and the Nigeria Economy: A theoretical perspective, 1986-2018”, European Journal of Accounting, Finance and Investment, Vol. 4, No. 1; 2018, ISSN (3446-7037)

Orumie, C. (2016), "The effect of unemployment rate and population growth on the Gross Domestic Product of Nigeria", International Journal of Applied Science and Mathematics, Vol. 3, issue 1, ISSN(online): 2394-5894

Sara Evans, "Bayesian Regression Analysis", Electronic Theses and Dissertations. Paper 412

Andrew Gelman, John B. Carlin, Hal S. Stern, Donald B. Rubin (2003), "Bayesian Data Analysis”, page 351-385

Jon Starkweather, PhD (2011), "Bayesian Generalized Linear Models in R”, page 2-12

Zellner, A. (1981), “Applications of Bayesian Analysis in econometrics”. The Statistician 32, page 2334

Abraham, W. (1986), “Bayesian Inference”. The American Statistician 40(2): 109: 110 